\title{
Hard-alloy coating for cutting and pressing tools by electric impulse technology
}

\author{
Sergey V. Novikov, Pavel Yu. Peretyagin ${ }^{a}$, Yurit O. Pristinskiy, Pavel D. Fokin \\ AND GaIK V. OGANYAN
}

Moscow State University of Technology "STANKIN", 1 Vadkovsky per., 127994 Moscow GSP-4, Russian Federation

Received 23 September 2015, Accepted 2 October 2015

\begin{abstract}
The progressive electric impulse method of hard-alloy coating for cutting and pressing tools is developed. The results of research showed influences of the structure formation for hard-alloy coating of the powders by hybrid treatment of the electric impulse and mechanical pressure.
\end{abstract}

Key words: Carbide coating / powder materials / electric current impulse / cutting tool / pressing tool / electro impulse sintering

\section{Introduction}

Continuous increase of use of hard-to-process materials in modern industry branches results in continuous growth of use hard-alloy tools and places ever-increasing requirements to their quality [1].

Hard alloys having exclusively high properties in principles are required only at tool cutting edges and surfaces. The rest of tool in most of the cases is advisable to make from steel. Existing process supposes tool stage manufacturing and this represents long-term and labor intensive production cycle. First the start hard-alloy plates are manufactured by powder pressing and sintering and then they are connected with steel casing by all possible ways. The most simple and economical way of hard alloy connection with steel is soldering. However occurrence of residual thermal stresses in soldering process results in occurrence of micro-fraction and cracks in hard-alloy plates causing tool damage both at manufacturing and in process of its operation: cutting tool losses due to plate damage are $50 \%$, including $10-15 \%$ at its manufacturing [2]. Other connection ways are low-productive and also do not prevent residual stresses.

Tool with mechanical connection of hard-alloy plates to steel casing has become widely used. Without any doubt in practicability of use of such tool it shall be noted the following. High economic effect from replacement of soldered tool with hard-alloy mechanically connected tool is associated not only because of its high quality [2], but also due to low quality of soldered hard-alloy tools [2]. In this work it is also noted that if there was process, which

${ }^{a}$ Corresponding author: p.peretyagin@stankin.ru allows reducing significantly level of thermal stresses at soldering or eliminates them in general, this effect should be far less and in some cases simply absent. Moreover replacement of soldered tool with hard-alloy plate mechanically connected tools in some cases is not possible and practical. That's why issues of development of production process of quality connection of hard alloy with steel remain rather actual.

Promising direction in improvement of hard-alloy tool and its manufacturing process is use of different methods of application of powder material coatings, permitting to combine in one operation the formation of hardalloy layer and its connection with steel casing, and this result in significant cost saving in tool-making industry. Coating application gas thermal methods such as gasplasma, plasma and detonation, have got maximum use. However small thickness of applied coatings, low physicalmechanical properties, non-optimal phase composition and structure of hard-alloy coating, high level of residual thermal stresses make these methods impractical for manufacturing of hard-alloy tools and becoming of soldering alternative [3]. To increase serviceability of hard-alloy cutting plates methods of coating mechanical and chemical precipitation have been developed [4]. However these methods also prevent from obtaining of certain thickness hard-alloy layers at steel bases with sintered hard alloy structure.

In some cases to generate hard alloy powder coatings laser beam power has been used [5]. And structure of obtained coatings has the same defects (not large coating thickness, unevenness of structure, porosity etc.) as above. 
Tasks of obtaining of coatings are also solved by impact-wave treatment methods [6]. In this case bond between powder particles and base and particles is formed due to wave processes, occurred in medium and created significantly non-uniform in time and space effect at material. Impact-wave input of power to hard-alloy powders is accompanied with additional damage of brittle particles, their restructuring and mechanical wedging at significant increase of hardness, micro deformation level, density of dislocations and other defects of crystal structure. Increased level of micro and macro stresses is often the cause of coating crack formation. Moreover after load waves as a rule it comes unloading waves, which may result in decrease of strength properties and even damage of obtained articles.

Recently methods of powder material sintering and coating application based on electric current use have got significant development. These processes are characterized with volumetric effect, high productivity and do not require protective atmosphere with wide range of control of temperature-power parameters. They provide simplicity of process equipment and permit to apply coating with thickness around ten millimeters [4], etc. Therefore it is promising to use possibilities of electric impulse technologies of powder material coating application for manufacturing of hard-alloy tools. In view of our analysis of physical basis of existing electric impulse methods of powder coating application and their interaction with structure and properties of obtained coatings it has been shown that the most promising methods are methods based on direct transmission of high-voltage impulse of electric current from condenser battery via hard allow powder in combination with mechanical load [4]. However it shall be noted that electric impulse and mechanical effect at powder materials under certain conditions may result in intensive mass transfer, formation of extremely non-uniform structure in article volume and even its damage due to electric explosion. Thus use of high voltage impulses of electric current and mechanical load for application of coating of hard allow powders at steel tool requires creation of experimental process equipment and also conduction of studies of physical processes occurred in these materials under such effect and determination of their effect at structure and final properties of obtained tool. This permits to create scientific basis of electric impulse technology of application of powder hard alloy coatings at steel tools.

This article discusses development of scientific basis of electric impulse technology of application of powder hard alloy coatings at steel tools.

\section{Mathematic modeling}

Physical processes occurred at electric impulse effect are rather complex and this makes difficult to interpret and set full-scale experiments. This is associated with significant instability and low duration of process of interest, availability of high intensity electric magnetic fields. In such cases the most effective research approach is mathematic modeling and simulation experiment. In this regard mathematic model of technological process of hard allow coating electric impulse application has been developed.

Initial set of equations has determined with laws of conservation of mass, impulse, energy together with electrodynamics formulas for compact and powder conducting media. This set of equations is supplemented with corresponding equation of state. For compact material Hook's law fulfilment is assumed. Equation of state of powder material is determined on the basis of experimental data. Solution of complete set of equations with corresponding initial and limit conditions identifies patterns occurred at coating electric impulse application. General pattern of process of interest is as follows. High voltage impulse passing via hard alloy powder, steel template and electrode-punch (molybdenum) intensively heats only hard alloy powder without significant heatup of electrode-punch and template. This occurs because specific electric resistance of powder is much higher comparing with specific electric resistance of compact materials of electrode-punch and template. At intensive powder heat-up its resistance to plastic deformation is dropped rapidly and under mechanical pressure powder material is consolidated with deformation representative rate, permitted by used loading system. Along with this heat transfer is occurred powder material to electrode-punch, press mould and template and their heat-up by heat conductivity. These processes have their characteristic time scales. Analysis of numerical evaluation of time parameters has shown that at electric impulse application technology as a rule it is executed the following ratio between characteristic time scales:

$$
t_{0}<t_{1} \ll t_{2}
$$

where $t_{0}$ is current impulse duration; $t_{1}$ is coating powder material consolidation time; $t_{2}$ is cooling time due to heat conductivity.

This ratio permits to solve sequentially complete set of equations. From the start problem of current density distribution in powder material shall be considered. According to known current density it may be determined heat-up temperature of powder material. Knowing dependence of powder medium visco-plastic properties on temperature consider powder material consolidation process. Cooling of powder layer and heating of template and electrode-punch due to heat conductivity process are examined simultaneously. After consolidation process it is continued template cooling with coating application and formed residual stresses in coating and template due to difference in thermal expansion coefficients. Phase micro stresses are also occurred. Conditions of occurrence and value of residual stresses are calculated within proposed mathematic model.

Conducted analysis of residual thermal stresses has shown that the higher mechanical load rate the less depth of template will be heated. In this case residual thermal stresses will be localized in heat-affected zone near interaction surface. Bulk of both solid alloy and template material will be free of these stresses. As result of work it 
has been obtained criterion permitting to identify range of application parameters, at which bulk of hard alloy coating is free from residual thermal macro stresses:

$$
H \gg \sqrt{\chi t_{\phi}}
$$

where $H$ is coating thickness; $\chi$ is steel template thermal conductivity; $t_{\phi}$ is coating forming time.

And it shall be considered that at sufficiently high rates of hard alloy powder loading the formation of compression wave with steep front is possible. Large gradient of current velocity at front will result in more intensive bond displacement relative to carbide grains. And nonuniform structure of hard alloy coating with depleted bond zones is formed. Moreover it shall be noted that coating is formed under mechanical pressure and this results in occurrence of compression stresses in it, which are beneficial for hard alloy. In coating the formation of phase micro stresses associated with difference in thermal extension coefficients between tungsten and cobalt carbide is also possible. Particles of tungsten carbide may be both matrix surrounded and contacted between each other. Conducted analysis has shown that contact thermal stresses at non-uniform structure are at sequence higher those at ideal agitation of components. Thus at preparation of powder mixture it is necessary to seek maximum uniform mixing of components.

On the basis of mathematical simulation optimum parameters of process of electric impulse hard alloy coating application at press and cutting tool have been calculated. Optimum parameters are the following: mechanical load rate is $1-10 \mathrm{~m} \cdot \mathrm{s}^{-1}$, electric current impulse duration is $<10^{-3} \mathrm{~s}$, current density is $j>50 \mathrm{kA} \cdot \mathrm{cm}^{-2}$.

\section{Development of electric impulse plant for coating application}

To implement electric impulse application method and to study process of coating formation from the powders electric impulse plant has been developed. Plant comprises the following main parts: current impulse generator and device for mechanical and electric power supply to coating formation zone (Fig. 1).

Principle diagram of current impulse generator (CIG) is given at Figure 1. CIG comprises charger 1, capacitor bank 2, and electronic commutator 3. Charger 1 is used for capacitor bank 2 charging and consists of step-up (up to $7 \mathrm{kV}$ ) transformer with $2 \mathrm{kWt}$ capacity and rectification circuit. Current limiting resistance is connected in series with rectification circuit. Capacitor bank 2 is energy accumulator. Capacitor bank energy at $5 \mathrm{kV}$ is $50 \mathrm{~kJ}$.

Because CIG uses high voltage in accordance with safety rules it has metal grounded guard rail and is equipped with systems of mechanical (disconnector) and electric (feeder) interlocks, preventing personnal electric shock. Earthing stick is used in CIG as auxiliary protective mean.

CIG is controlled with control unit which comprises measuring and recording instruments and is used for controlling of mechanical and electric interlocking, capacitor bank charging and discharging and also current impulse parameter recording. Current impulse recording system 5 comprises Rogovskiy coil. Rogovskiy coil is the best choice at creation of measuring systems in electric networks because it ensures simplicity of use for most of base measuring circuit and matches all requirements both according to measuring range and accuracy. Rogovskiy coil is toroidal coil located around primary wire in the same way as secondary winding in common current transformer but without ferromagnetic core.

Sensor output signal voltage is proportional to current derivative:

$$
U=M \frac{\mathrm{d} J}{\mathrm{~d} t}
$$

where $M$ is mutual inductance between current conductor and coil.

Device for electric and mechanical power supply comprises pneumatic press generating load at compactable powder and working position, where process of electric impulse application is performed.

\section{Hard alloy coating structure and properties}

Study of effect of application parameters (pressure $P$, current amperage $J$ ) at structure and properties of obtained hard alloy coatings has been performed using developed electric impulse plant. Study has been performed using industrial hard alloy powder VK-10 without $\sigma \mathrm{e} 3$ plasticity agent. This is because hard alloys of tungsten-cobalt group are wide-spread in industry and have the best properties. As material of reinforced tool st. 45 (analogue of $\mathrm{C} 45 \mathrm{E}$ ) and HVG (analogue of $107 \mathrm{WCr} 5$ ) tempered steel has been used. In process of work parameters of application allowing high quality hard alloy coatings are determined. At metallographic examination of their structure it has been found, that hard alloy coating structure consists of two phases: crystals of tungsten carbide and sections of cobalt binding phase (Fig. 2). Presence of excessive graphite phases and $\eta_{1}$ has not found and this means carbon balance retention in process of coating formation. And coating has more fine grain of $W C$-phase comparing with melt, sintered according to standard process and $C_{0}$ - phase is enriched with $W$ and $C$ up to limit value (Fig. 3 shows microstructure of hard alloy VK-10 obtained according to standard process for comparison and Table 1 contains results of microstructure analysis). It shall be also noted that most of $W C$ grains have rounded nature and this means absence of crystalline modification in process of coating electric impulse application. At X-ray study of obtained hard alloy coatings it has been found relatively weak crustal texture. Observed texture is formed at determining effect of plastic deformation, but it is not improbable that corresponding crystalline modification somehow contributes to it. Texture nature is explained in proposal that slip systems $\{$ IOIO $\}$ $\langle\mathrm{OOOI}\rangle$ are active in tungsten carbide at application temperature.

Study of structure and composition of contact zone of VK-10 (analogue of MC241: WC-90\%, Co-10\%) hard 


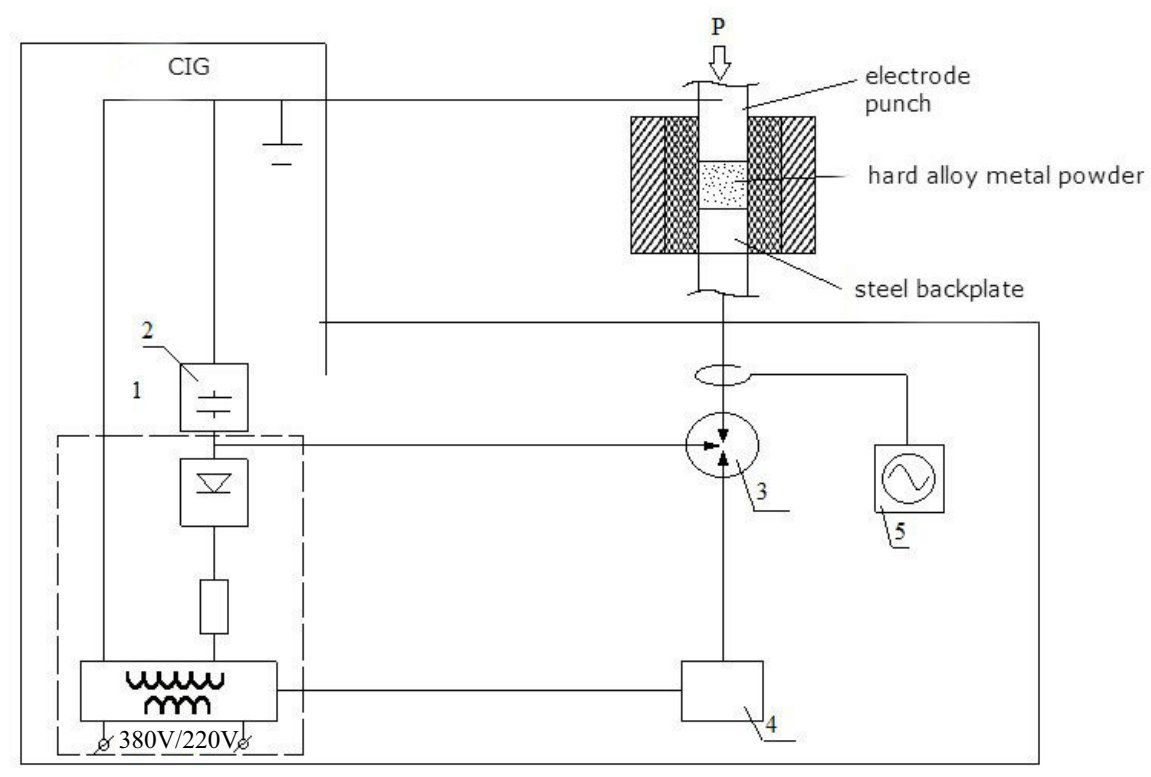

Fig. 1. Principal diagram of electric impulse plant for powder hard alloy coating application.

Table 1. Results of study of micro-structure of VK-10 hard alloy coating obtained using electric impulse process and VK-10 hard alloy obtained using standard process.

\begin{tabular}{|c|c|c|c|c|c|c|c|c|c|c|c|}
\hline \multirow[t]{2}{*}{ Process } & \multirow[t]{2}{*}{$\begin{array}{l}\text { Porosity degree, } \\
\text { \% vol. }\end{array}$} & \multirow{2}{*}{$\begin{array}{c}\text { Availability of } \\
\text { large pores with } \\
\text { size }>50 \mu \mathrm{m}\end{array}$} & \multirow[t]{2}{*}{\begin{tabular}{c|} 
Cobalt phase \\
distribution
\end{tabular}} & \multirow{2}{*}{$\begin{array}{c}\text { Graphite } \\
\text { availability, } \\
\text { \% vol. }\end{array}$} & \multirow[t]{2}{*}{\begin{tabular}{|c|}
$\eta_{1}$ phase \\
availability
\end{tabular}} & \multicolumn{6}{|c|}{$\begin{array}{c}\text { WC fraction distribution } \\
\% \text { vol. }\end{array}$} \\
\hline & & & & & & $1 \mu \mathrm{m}$ & $2 \mu \mathrm{m}$ & $3 \mu \mathrm{m}$ & $4-5 \mu \mathrm{m}$ & $6-7 \mu \mathrm{m}$ & $8-10 \mu \mathrm{m}$ \\
\hline $\begin{array}{l}\text { Electric } \\
\text { impulse }\end{array}$ & $0.08 \mathrm{~A}$ & $\mathrm{n} / \mathrm{a}$ & $\begin{array}{c}\text { uniform, } \\
\max 1.5-2 \mu \mathrm{m}\end{array}$ & $\mathrm{n} / \mathrm{a}$ & $\mathrm{n} / \mathrm{a}$ & 37 & 35 & 22 & 6 & - & - \\
\hline Standard & $0,02 \mathrm{~A}$ & $\mathrm{n} / \mathrm{a}$ & \begin{tabular}{|c|} 
uniform, \\
$\max 1-1.5 \mu \mathrm{m}$
\end{tabular} & 0.3 & $\mathrm{n} / \mathrm{a}$ & 23 & 32 & 20 & 16 & 6 & 3 \\
\hline
\end{tabular}

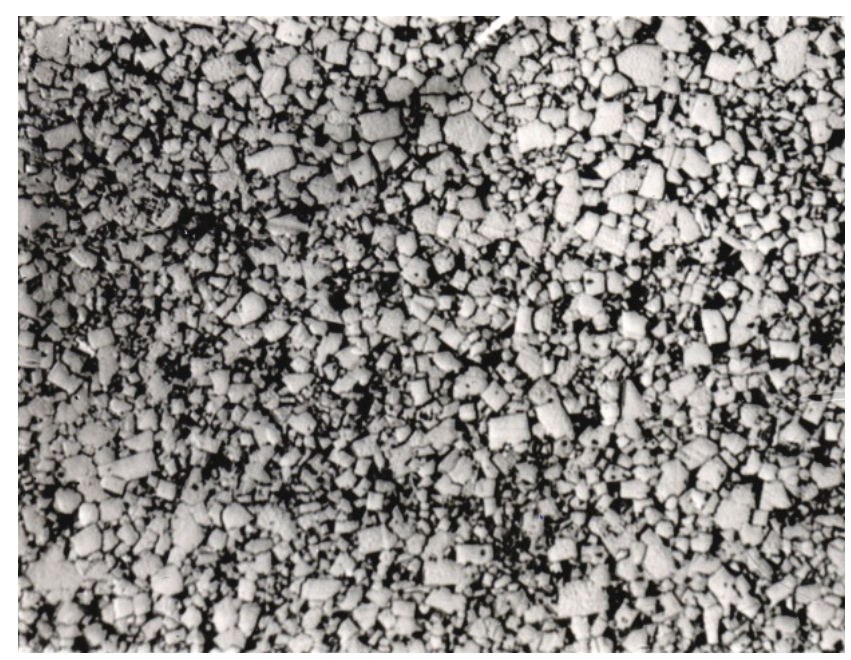

Fig. 2. Microstructure of VK-10 hard alloy coating obtained using electric impulse process, $\times 1250$, etched.

alloy with st. 45 and HVG steel has been conducted by metallographic methods and X-ray microanalysis. Cracks

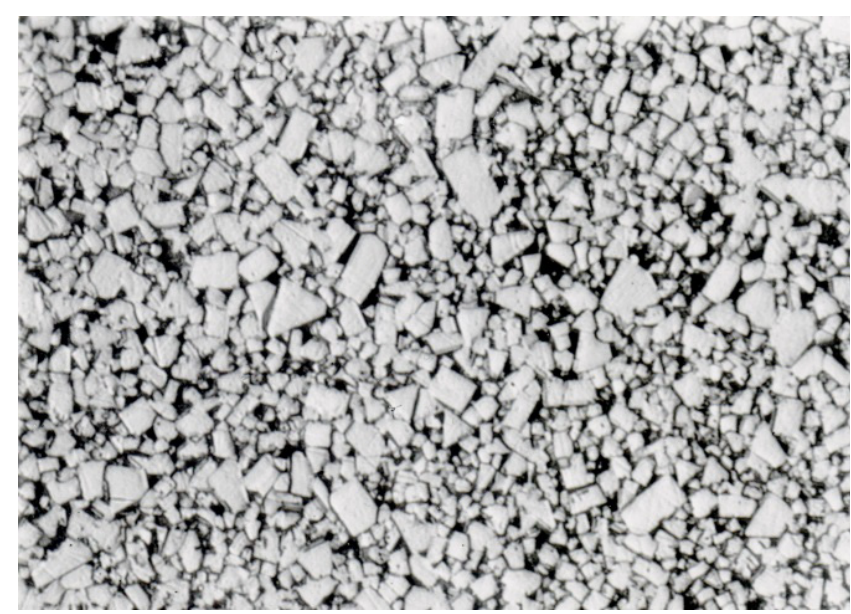

Fig. 3. Microstructure of VK-10 hard alloy obtained using standard process, $\times 1250$, etched.

have been detected at study of contact zone microstructure. Occurrence of cracks is associated with high level of residual thermal stresses in contact zone of hard alloy 
coating with steel template, which according to calculations made using mathematic model reach maximum in this zone. To reduce level of residual thermal stresses in transient zone between hard alloy coating and steel template in following experiments PZh2-M3 (composition: $98,4 \%$ of Fe powder, particle size $150-200 \mu \mathrm{m}$ ) iron powder flexible interlayer has been introduced and this permitted in the following to obtain defect free connection of hard alloy coating with steel template. Near interface region after etching of hard alloy coating with Murakami solution it has been detected availability of $\eta_{1}$ phase and this is likely to be associated with hard alloy decarbonisation due to gradient of carbon concentration in connection area. However it is shall be noted that $\eta_{1}$ phase has been detected also at diffusion welding in vacuum. At the same time as it is known strength properties of such combinations are relatively high. Strength of hard alloy (VK)steel bond made under optimal conditions of diffusion welding is: shear 392-450 MPa, twisting 274-294 MPa, elongation 588-882 $\mathrm{MPa}$ [1]. By comparison the highest shear strength of soldered connection is $280 \mathrm{MPa}$ [2].

At obtained samples using JSM-35CF electronic scanning microscope (JEOL, Japan) it has been studied element distribution in transient zone between coating, transitional interlayer and template. At detected relative flat sections of samples with $\times 1000$ magnification it has been studied element distribution in hard alloy depending upon analyzed layer depth. The study has shown that in coating layer at least $50 \mu \mathrm{m}$ deep adjoining to contact surface samples of interest do not actually contain cobalt. Penetration of tungsten and cobalt in steel template also has not been detected.

Hard alloy coating electric impulse formation is process occurred in relatively small volume. Availability of concentrated heat source, high heating rate and intensive heat removal to template results in its structural changes. At metallographic study of microstructure and determination of micro-hardness it has been found that HVG steel template heat affected zone is $\sim 0.5 \mathrm{~mm}$ and for 45 steel $\sim 0.2 \mathrm{~mm}$. For comparison it shall be noted that at electric contact baking heat affected zone is $1.5-1.8 \mathrm{~mm}$, at gas-flame built-up welding $24-30 \mathrm{~mm}$, at plasma builtup welding 4-8 mm, at arc built-up welding 5-20 $\mathrm{mm}$ [4]. Measurement of micro-hardness has shown that at application of coating with electric impulse process strengthening of template surface layer has happened. And actually step change of micro-hardness at transition to base metal is observed. Structure of heat affected zone is martensite and its micro-hardness is $9800 \mathrm{MPa}$ for HVG steel (base metal micro-hardness is $3900 \mathrm{MPa}$ ), $5400 \mathrm{MPa}$ for 45 steel (base metal micro-hardness is $2000 \mathrm{MPa}$ ). Observed effect of surface strength increase may be used in development of new strengthening technological processes.

Comparing results of micro-analysis and metallography it can be concluded that transient zone between hard alloy coating and steel template comprises tungsten carbide, iron and $\eta_{1}$ phase. This structure of transient layer despite availability of $\eta_{1}$ phase provides connection of hard alloy coating and steel template with strength prop- erties matching connected materials: at determination of bond strength of hard alloy coating applied at steel using electric impulse process damage has occurred in hard alloy without reaching of connection zone. It shall be noted that availability of $\eta_{1}$ phase in connection zone of hard alloys, obtained using electric impulse process may be excluded using carbon free powder materials as transient interlayer. For instance nickel, copper etc. and this without question will be used at following development of this paper.

Physical-mechanical and cutting properties of material of hard alloy coating obtained using electric impulse process under optimum conditions from VK-10 powder have been determined. Their results are shown in Table 2.

Study of physical-mechanical properties has shown that obtained values of coating material properties obtained using electric impulse process match alloy obtained using standard process (pressing with following sintering). And increase of coating material hardness obtained using electric impulse process is observed. Hardness increase is associated with more fine grain of carbide phase and coercitive force $\left(H_{\mathrm{C}}\right)$ higher values and metallographic analysis data have indicated about this.

Results of determination of cutting properties under laboratory conditions are given in Table 3. Wear strength has been tested at grey cast iron using the following cutting conditions: $V=110 \mathrm{~m} \cdot \mathrm{min}^{-1}$, feed $S=0.2 \mathrm{~mm} \cdot \mathrm{rev}^{-1}$, cutting depth $t=1 \mathrm{~mm}$. VK-8 (analogue of MC241: WC-92\%, Co-8\%) hard alloy sintered according to standard process has been selected as reference specimen.

Testing has shown that cutting properties $\left(K_{\mathrm{CT}}\right)$ of VK-10 alloy produced using electric impulse process at the first testing are equal to VK-8 reference alloy and at the second testing are 2.5 times higher. It shall be noted that VK-10 produced using standard processes from the same powder mixture as for electric impulse process have $1.2 \mathrm{~mm}$ wear in $5 \mathrm{~min}$ and this is significantly below than strength of experimental alloy. Increase of cutting properties of alloys obtained using electric impulse process is associated with more fine grain of carbide phase and strengthening of cobalt bond with tungsten and carbon.

Performance testing of experimental tools with coating obtained using electric impulse process from VK-10 hard alloy powders has been conducted under conditions of mass and trial productions at nuclear industry facilities. Pilot batches of pressing tools (punches for high abrasive powder pressing) and straight-cutting tools have been manufactured. Figure 4 shows appearance of punch with hard alloy coating.

Tests have shown that typical withstand strength of experimental pressing tools with hard alloy coating obtained using electric impulse process from VK-10 powder is actually 2 times higher than withstand strength of tempered HVG steel tools.

Performance testing of experimental straight-cutting tools with hard alloy coating obtained using electric impulse process from VK-10 powder has shown that withstand strength of experimental straight-cutting tools is 
S.V. Novikov et al.: Mechanics \& Industry 16, 704 (2015)

Table 2. VK-10 hard alloy coating physical-mechanical properties (comparison analysis).

\begin{tabular}{ccccc}
\hline Process & $\rho$, g.cm & $K_{\mathrm{IC}}, \mathrm{Mpa} \cdot \mathrm{m}^{1 / 2}$ & $\mathrm{HV}, \mathrm{kg} . \mathrm{mm}^{-2}$ & $H_{\mathrm{C}} \mathrm{kA} \cdot \mathrm{m}^{-1}$ \\
\hline Electric impulse & 14.6 & 12.2 & 1320 & 12.6 \\
Standard & 14.7 & 13.1 & 1200 & 7.7 \\
\hline
\end{tabular}

Table 3. Cutting testing results.

\begin{tabular}{cccc}
\hline Alloy grade & Efficient life, min & Wear, mm & $\begin{array}{c}\text { Withstand strength } \\
\text { coefficient, } K_{\mathrm{CT}}\end{array}$ \\
\hline VK-8 (reference) & 11.0 & 0.8 & 1.0 \\
VK-10 (electric impulse) & 10.0 & 1.1 & 0.9 \\
VK-8 (reference) & 10.5 & 0.5 & 1.0 \\
VK-10 (electric impulse) & 14.0 & 0.23 & 2.5 \\
\hline
\end{tabular}

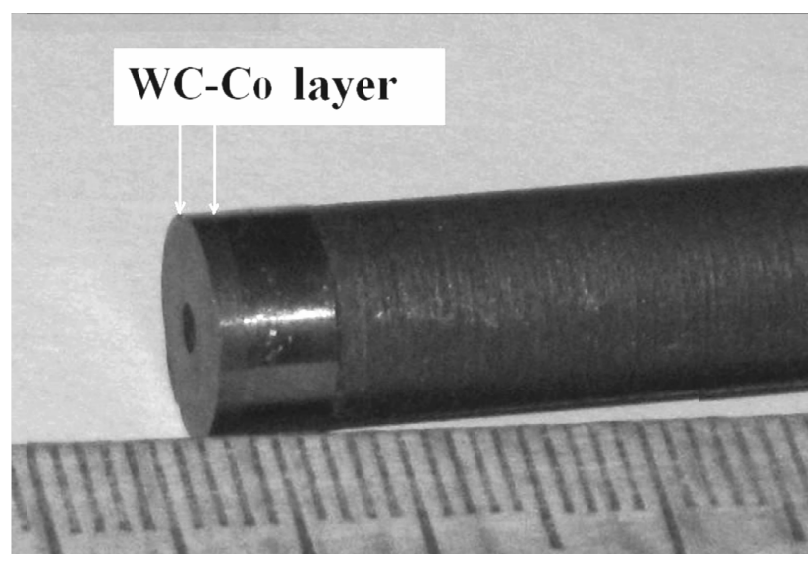

(a)

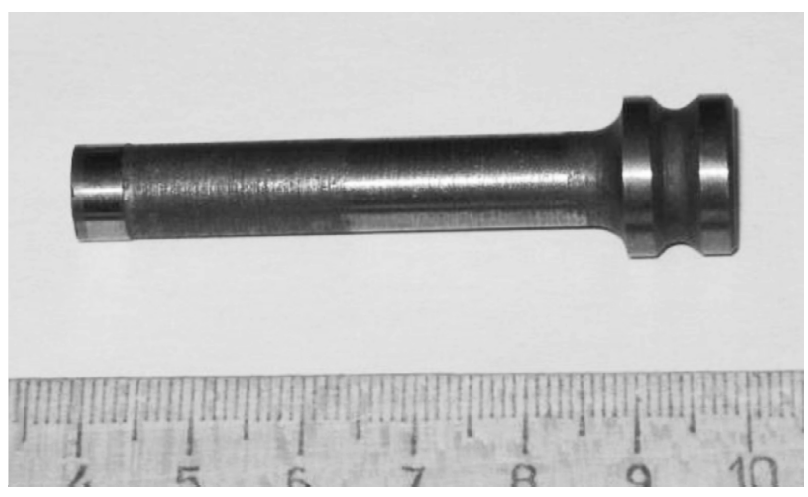

(b)

Fig. 4. Appearance of punch with hard alloy coating obtained using electric impulse process.

$T=156 \pm 10 \mathrm{~min}$. At control tests of standard soldered tools with VK-8 hard alloy plate its withstand strength has been $T=91 \pm 21 \mathrm{~min}$. From these data one can see that according to withstand strength maximum values experimental tool exceeds standard tools significantly. As wear criterion flank wear has been selected. $0.5 \mathrm{~mm}$ flank wear has been considered as bluntness criterion. Testing has been conducted under factory conditions at lathe $16 \mathrm{~K} 20$ model normal accuracy turning lathe by $12 \mathrm{X} 18 \mathrm{H} 10 \mathrm{~T}$ (analogue of X10CrNiTi18-10) stainless steel bar linear turning. This material has been selected because stainless steel is most typical and widely used material used at nuclear industry facilities. All cutting tools have been tested under the same cutting conditions: $V=70 \mathrm{~m} \cdot \mathrm{min}^{-1}$, feed $S=0.2 \mathrm{~mm} \cdot \mathrm{rev}^{-1}$, cutting depth $t=1 \mathrm{~mm}$, which correspond to typical semi finished conditions of treatment of this class materials. Cutting has been performed using ET-2 (composition based on mineral oil and salt of high molecular organic acid) emulsolbased common lubricating and cooling fluid (LCF).

It shall be noted that increase of cutting properties has been achieved at use of hard alloy powder with less content of tungsten carbide (in our case VK-10 instead of VK-8). However discontinuity of experimental tool cutting properties is higher comparing with standard tool. Increase of uniformity of cutting properties of tools with hard alloy coating obtained using electric impulse process will be subject of follow-up studies.

\section{Conclusion}

Conducted studies to reveal patterns of formation of hard alloy coating structure from powders at their application using high-power impulse of electric current in combination with mechanical pressure permit to develop progressive electric impulse method of application of hard alloy coatings at tools.

Further development of electric impulse process (EIP) of application of hard alloy coatings from powders depends upon solution of set of questions issues. High importance has assumed further studies of physical processes occurred at EIP of application of hard alloy coatings permitting to understand and interpret mechanism of action of electric current, magnetic field generated by it, high temperatures and mechanical pressure at formation of structure and properties of final coatings. On this basis mathematic model of technological process of interest shall be improved. The purpose of modeling is to optimize EIP of application of hard alloy coating from powders on the basis of digital simulation at maximum reduction of full-scale experiments.

Process equipment will be prominent in transition to mass production. Here it is required solution of 
its operation life questions. In particular withstand strength of pressing tools under conditions of action of high-power electric-magnetic fields, high temperatures in combination with mechanical pressure will be highpriority problem.

Great opportunities have use of hard alloy nanopowders as coating material. Trial experiments have shown possibility of retention of initial powder particle nano-dimensions in obtained hard alloy coating using EIP and this is associated with short-duration of technological process.

Wide use of EIP for application of powder hard alloy coatings will be economically feasible due to low energy consumption and high efficiency of electric power use, simplicity of process equipment (no complex vacuum, optic, electronic and ion-beam systems), possibility to make automated equipment and obtain state-of-art hard alloy coating tools with improved physical-mechanical properties, unavailable using conventional processes. This process is implemented completely at home equipment and materials.

Acknowledgements. Authors would like to thank The Ministry of the Russian Federation supported this work in the frame of Governmental Regulation of the Russian Federation No. 220, 9 April 2010 by contract 14.B25.31.0012, 26 June 2013.

\section{References}

[1] L. Esteban-Tejeda, L.A. Díaz, C. Prado, B. Cabal, R. Torrecillas, J.S. Moya, Calcium and Zinc Containing Bactericidal Glass Coatings for Biomedical Metallic Substrates, Int. J. Mol. Sci. 15 (2014) 13030-13044

[2] A. Centeno, V.G. Rocha, B. Alonso, A. Fernández, C.F. Gutierrez-Gonzalez, R. Torrecillas, A. Zurutuza, Graphene for tough and electroconductive alumina ceramics, J. Eur. Ceram. Soc. 33 (2013) 3201-3210

[3] L.A. Díaz, M.A. Montes-Morán, P.Y. Peretyagin, Y.G. Vladimirov, A. Okunkova, J.S. Moya, R. Torrecillas, Zirconia-alumina-nanodiamond composites with gemological properties, J. Nanoparticle Res. 16 (2014) 1-9

[4] A.S. Vereschaka, S.N. Grigoriev, E.S. Sotova, A.A. Vereschaka, Improving the Efficiency of the Cutting Tools Made of Mixed Ceramics by Applying Modifying Nanoscale Multilayered Coatings, Adv. Mater. Res. 712 (2013) 391-394

[5] V.V. Molodtsov, A.A. Okunkova, P.Y. Peretyagin, Manufacture of graphite electrodes for the electrospark machining of complex high-precision components, Russian Eng. Res. 32 (2012) 550-552

[6] A.B. Nadykto, F. Yu, M.V. Jakovleva, J. Herb, Y. Xu, Amines in the Earth's atmosphere: a density functional theory study of the thermochemistry of pre-nucleation clusters, Entropy 13 (2011) 554-569 